\title{
OVERVIEW OF HYDRAULICS AND SIMIYU RIVER SEDIMENT INPUT INTO MAGU BAY, LAKE VICTORIA, TANZANIA
}

\author{
Alfonse M. Dubi \\ Institute of Marine Sciences, University of Dar es Salaam \\ P.O. Box 668 Zanzibar, Tanzania \\ E-mail: $\underline{\text { dubi@ims.udsm.ac.tz }}$
}

\begin{abstract}
$\mathbf{L}$ ake Victoria is experiencing multifaceted environmental and ecological problems. A study of the problems needs a multidisciplinary approach to establish the cause-effect relationships. The study focuses on the hydraulics of Lake Victoria's Magu Bay and Simiyu riverine input of suspended sediments and their distribution in the Bay. Sampling in the river mouth and the Bay was conducted aboard an $8 \mathrm{~m}$ outboard engine wooden boat. Turbidity, currents speed and direction were measured using an "AANDERAA" multi-sensor self-recording current meter model 9 (RCM9). Water depth was measured using an echo-sounder type FISHIN'BUDDY II. Geographical positions of the sampling locations were obtained using a GPS, Model Garmin 12. Suspended sediment concentrations were determined by sampling the water, filtering and weighing the sediments. Data on rainfall and water discharge were obtained from the Mwanza Meteorological office. Statistical analysis shows that cumulative rainfall of $1043 \mathrm{~mm}$ and the respective discharges of $98.5 \mathrm{~m}^{3} / \mathrm{s}$ have a return period of 5 years. A return period of 50 years is expected to have cumulative rainfall of $1403 \mathrm{~mm}$ and discharges of $156.7 \mathrm{~m}^{3} / \mathrm{s}$. Concentration of suspended particles was highest at the river mouth (1573 $\mathrm{mg} / \mathrm{l}$ at station 1$)$ and exponentially decreased as one moves away from the river $(0.9 \mathrm{mg} / \mathrm{l}$ at station 8 , a station that was most off-shore from the river mouth). Also, turbidity was higher towards the river and decreased as one moves away from the river mouth. In the first half a kilometre longitudinally from the river mouth, most of the suspended sediment has been deposited its concentration is attenuated exponentially as $\mathrm{C}_{\mathrm{s}} / \mathrm{C}_{\mathrm{so}}=\mathrm{e}^{-\mathrm{k}_{\mathrm{x}}}$, where $\mathrm{C}_{\mathrm{s}}$ is suspended sediment concentration at distance $\mathrm{x}$ from the river mouth and $\mathrm{C}_{\mathrm{so}}$ is concentration at $\mathrm{x}=0$ (at the river mouth) and $\mathrm{k}=2.1$ is the attenuation coefficient. Both surface and bottom currents exhibited the same trend as sediment concentration. At the mouth of the river, the surface and bottom current are northward. In the first half kilometre from the river mouth, the current speed has been strongly attenuated from $0.54 \mathrm{~m} / \mathrm{s}$ to $0.07 \mathrm{~m} / \mathrm{s}$. From there onwards, the current speeds are reversed, almost flowing in the opposite direction of the river flow. Simiyu River is a major sediment contributor to the bay ranging from zero on days when there is no water discharge to about 20,000 tons/day in the observed period. It is recommended that a comprehensive and long-term study to cover all river sediment input into the lake be undertaken.
\end{abstract}

Keywords: Lake Victoria, Magu Bay, hydraulics, sediment transport

\section{INTRODUCTION}

Lake Victoria, the greatest among the African Great Lakes and the third largest in the World, has a surface area of about $68,800 \mathrm{~km}^{2}$. The lake is shared by Kenya (6\%), Tanzania (49\%) and Uganda $(45 \%)$. The lake is generally shallow with average and maximum depths of $40 \mathrm{~m}$ and $80 \mathrm{~m}$ respectively. The lake occupies a crustal sag between the western and eastern rift shoulders, and was formed as a result of river reversal and ponding during the Cenozoic rifting (Johanson et al., 1996; Stager et al., 1997).

According to Mpendazoe et al. (1993); Hamza (1996) and Mtega and Masanja (1999), pollutant loading in Lake Victoria resulting from landbased activities has received substantial, though not adequate, attention. Non-point sources of material input into the lake have in many occasions been neglected and in most cases they are merely implicated by circumstantial evidences.

According to Lehman (1996) sedimentation is one of the many causes of ecological changes in the Lake. The accelerated rates of input of nutrients into Lake Victoria in the last four decades has been to a greater extent a result of direct and indirect anthropogenic activities in the watershed. For instance, the proliferating human population is inevitably creating pressure on land use in the catchment area. Land denudation with the concomitant soil erosion is a major problem in poorly managed agricultural, mining and human settlement 
areas. These activities exacerbate the Aeolian and fluvial transport of soil material, organic matter and nutrients. The main objective of the study is to determine riverine inputs of total sediment and particulate nutrients from the Simiyu river. The study focuses on water discharge, suspended sediment concentration, depositional features and pattern of surface currents in Magu Bay in Speke Gulf of Lake Victoria.

\section{STUDY AREA}

The site chosen for the present study was Magu Bay, in the Speke Gulf where Simiyu River discharges its water into Lake Victoria (Figure 1). Speke Gulf is the second largest gulf of Lake Victoria, located on the southeastern part of the lake and has a surface area of approximately $2425 \mathrm{~km}^{2}$. Magu Bay is in the Speke Gulf, with a surface area of approximately $78 \mathrm{~km}^{2}$ and it is one of the most lucrative fishing grounds in the Tanzanian waters of the lake. The Simiyu River catchment area is approximately $5320 \mathrm{~km}^{2}$ and is located between $33^{\circ} 15^{\prime}-35^{\circ} 00^{\prime} \mathrm{E}$ and 2o 30' - 3o 30' S. The Simiyu River drains the Serengeti National Park plains and partly Mau ranges in Kenya to the Lake Victoria on the downstream before it discharges its waters to the Lake Victoria.

The bay is shallow with depth ranging between $0.5 \mathrm{~m}$ in areas very close to shore, and $15 \mathrm{~m}$ at station 8 (approximately $15 \mathrm{~km}$ from Simiyu River mouth) as shown in Figure 2. In the shallow area close to the shore, most of the lake bottom is soft, laden with lots of detritus and large quantities of dead mollusk shells. At the entrance of the river to the lake and all along the river stretch the bottom is typically muddy or silty. Sandy areas occasionally appear at some points. Most of the shoreline along the bay and particularly at Simiyu river mouth, is fringed by dense reeds/sedges, especially Cyperus papyrus, but Phragmites sp., Vossia sp., Eichhornia crassipes, Pistia niloticus and Typha sp. are common in some areas of the bay. None of the beaches in the bay had extensive water hyacinth mats.

Available rainfall data spans from 1969 to 1997 collected at Ndagalu rainfall station (Station ID: 92.3346). Water discharge data spans from 1969 to 1985 and again from 1999 to 2000. Data is not available for the period between 1986 and 1998. Figure 3 shows cumulative annual rainfall recorded at Ndagalu Rainfall Station. The cumulative annual rainfall was highest in 1989 with a value of $1256 \mathrm{~mm}$ and it was lowest in 1969 with a value of $65.2 \mathrm{~mm}$. From 1969, the cumulative annual rainfall has generally been increasing with a linear trend of $y=15 x$ +621 . Figure 4 shows recorded water discharge recorded at Simiyu River Road Bridge (STATION ID: 01.12.02.2). 
Figure 1. Sampling stations in the Magu Bay, Lake Victoria

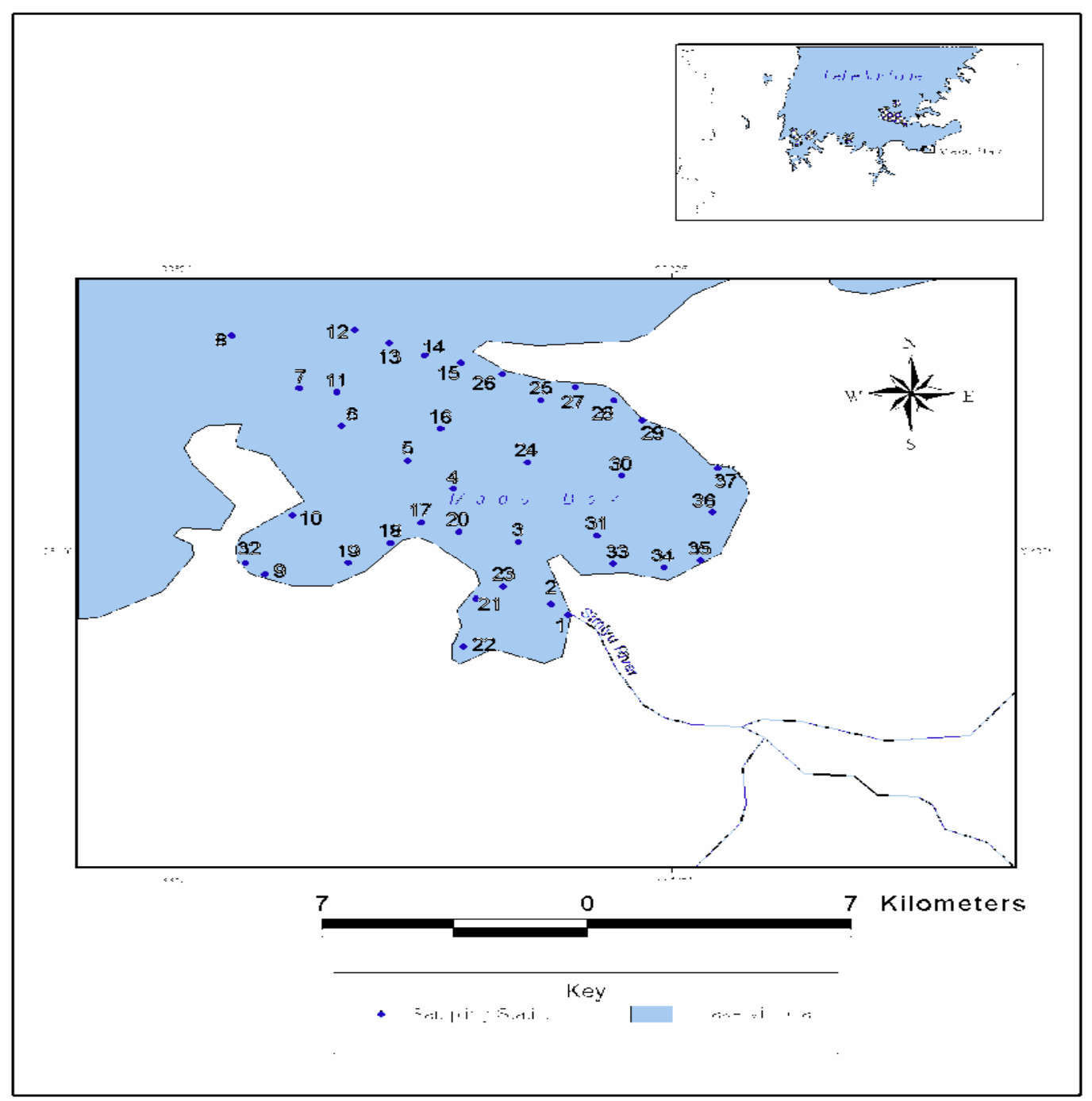




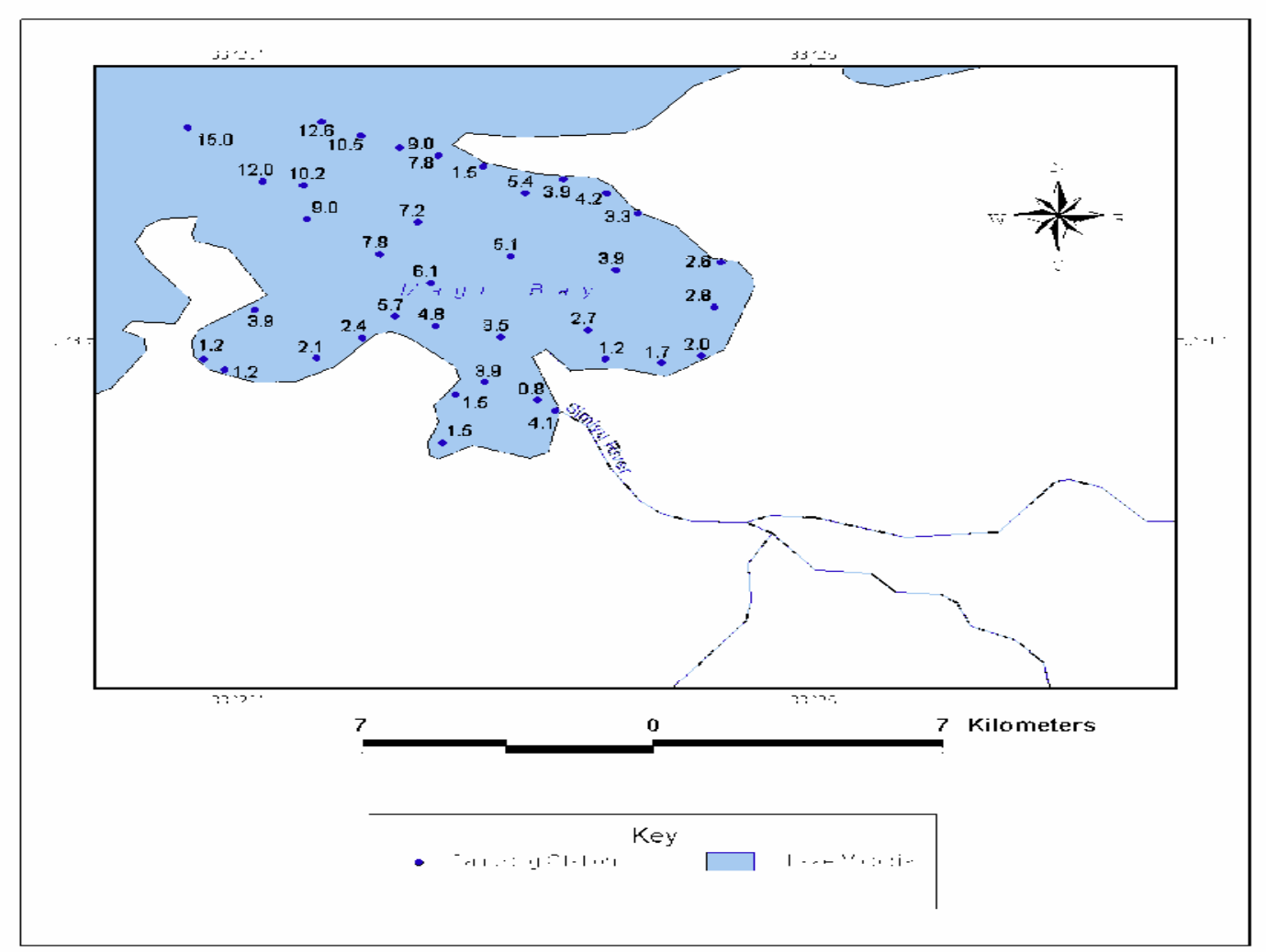

Figure 2: Water depths at sampling stations in the Magu Bay 
3 HYDRAULIC PROCESSES, SEDIMENT ANSPORT AND DISPOSITION

\subsection{Effect of widening of river mouth on water depth}

As the river enters the lake, the river mouth is suddenly widened. For a steady 1-D uniform flow the equation of continuity is given (e.g. Guo, 2002)

$Q=A V$

where $Q$ is the water discharge $\left(\mathrm{m}^{3} / \mathrm{s}\right), A$ is the cross-sectional area $\left(\mathrm{m}^{2}\right)$ of the river channel and $V$ is the average water flow velocity. For such steady flow conditions, Manning's equation is usually employed and the water discharge can be expressed as

$Q=\frac{1}{n} \frac{A^{5 / 3}}{P^{2 / 3}} \sqrt{S}$

Where $n$ is Manning coefficient and $P$ is the wetted perimeter and $S$ is the bed slope of the channel. If a rectangular channel is assumed, then

$A=B y_{n}$ and $P=B+2 y_{n}$

In which $B$ is the channel width and $y_{n}$ is the normal depth. Substituting Equation (3) into Equation (2) gives that

$Q=\frac{1}{n} \frac{\left(B y_{n}\right)^{5 / 3}}{\left(B+2 y_{n}\right)^{2 / 3}} \sqrt{S}$

If Equation (4) is written in a dimensionless form, i.e.

$\frac{n Q}{B^{8 / 3} \sqrt{S}}=\frac{\left(\frac{y_{n}}{B}\right)^{5 / 3}}{\left(1+2 \frac{y_{n}}{B}\right)^{2 / 3}}$

And defining $X=\frac{n Q}{B^{8 / 3} \sqrt{S}}$ and $Y=\frac{y_{n}}{B} \ldots(6)$
Then Equation (5) becomes $X=\frac{Y^{5 / 3}}{(1+2 Y)}$

Equations (6) and (7) shows that as the width of the channel increases to approach infinity $(\infty)$ and the discharge remains constant, the dimensionless depth $Y$ approaches zero and therefore Equation (7) becomes $Y=X^{3 / 5}$.

Similarly, as the channel width decreases to approach zero, Guo (2002) showed that $Y=2^{2 / 3} X$

The cross-point between the two asymptotic values given by Equations (8) and (9) is given by Guo (2002) as $X_{o}=2^{-5 / 3}=0.315$ such that

$$
\left.\begin{array}{ll}
Y=X^{3 / 5} & \text { for } \mathrm{X}>\mathrm{X}_{\mathrm{o}} \\
Y=2^{2 / 3} X & \text { for } \mathrm{X}<\mathrm{X}_{\mathrm{o}}
\end{array}\right\}
$$

\subsection{Effect of vegetation on flow velocity}

The vegetation found at the mouth of River Simiyu has a strong influence on physical and probably biological process. The presence of the reeds is directly linked to the hydraulic variables such as velocity and floor depth and their variation thereof. The influence of the vegetation on the physical processes such as flow velocity and flow depth can be described through resistance equations. In natural rivers such the vegetated Simiyu, resistance arises, in addition to boundary shear stress and surface roughness, also from a variety of other energy loss mechanisms associated with channel characteristics, including vegetation.

From a simple force balance analysis, James et al. (2004) suggested the use of a simple equation for flow through emergent vegetation. It is assumed that resistance through vegetation is dominated by stem drag, which depends strongly on the morphology of the stems. The drag force $\left(F_{D}\right)$ of a stem is related to local flow velocity $(V)$ by

$F_{D}=1 / 2 \rho C_{D} A_{s} V^{2}$

where $\rho$ is the density of water, $A_{s}$ is the projected area of the stem defined by the stem 
length and the diameter $(d), C_{D}$ is a drag coefficient depending on the stem size, shape and the stem Reynolds number given as,

$\operatorname{Re}=\frac{V d}{v}$ in which $v=1.14 \times 10^{-6} \mathrm{~m}^{2} / \mathrm{s}$ is the kinematic viscosity for water at $20^{\circ} \mathrm{C}$

By measuring the drag force, $C_{D}$ is commonly presented graphically as a function of $R e$.

The conventional free surface flow resistance equations can be developed from the balance of forces driving and resisting the water movement. The driving force originates in the down-slope weight component of the water, and the resisting force in the shear stress imposed by the boundary. The balance of these forces leads to a dependence of the boundary shear stress on flow depth, and a combination of this with an assumed relationship between boundary shear stress and velocity leads to an equation for velocity as a function of flow depth. However, if the resistance to flow is exerted by the stem drag rather than boundary layer, the velocity is independent of flow depth. For a steady uniform flow of a unit width element in a macrophyte-dominated flow, and equating the driving force (down slope weight of component of element) to the resisting force, which is the sum of drag forces from all stems within the element, James et al. (2004) gives:

$$
\psi_{n}=\left(L-\frac{m \pi d^{2}}{4}\right) S=1 / 2 \rho C_{D}\left(m y_{n} d\right) V^{2}
$$

where $\gamma=\rho g$ is the unit weight of water, $g$ is the gravity acceleration, $m$ is total number of stems within the element, $L$ is the length of the element and $S$ is the slope of the channel. Rearranging Equation (13) and taking the number of stems per unit area $N=m / L$, the flow velocity is obtained as:

$V=\frac{1}{F} \sqrt{S}$
$\frac{1}{F}=\sqrt{\frac{2 g}{C_{D} N d}\left(1-\frac{N \pi d^{2}}{4}\right)}$

The resistance coefficient depends on stem density, stem diameter and drag coefficient. By measuring the slope, discharge and flow depth values, values of $F$ can be calculated. As the flow depth increases the relative contribution of bed shear to resistance becomes small. However, for low flow depths, sparse stem densities and very rough boundaries the influence of the bed shear on overall resistance can be expected to be important. Under these conditions, and in the absence of stems, the shear stress increases linearly with depth to a maximum value, where it is balanced by the shear stress at bed. For a unit width within a wide uniform flow in the presence of stems, part of the down-slope component of the flow is carried out by the stem and the bed shear is reduced. Consequently, the actual bed shear can be expressed as

$\tau_{o}=\left(1-\frac{N \pi d^{2}}{4}\right) \not y_{n} S-\frac{1}{2} \rho C_{D} N y_{n} d V^{2}$

However, the conventional free surface flow resistance equations are based on an assumed proportionality between boundary shear and average flow velocity and given as:

$\tau_{o}=a \rho V^{2}$

Combining Equation s (16) and (17) gives

$a \rho V^{2}=\left(1-\frac{N \pi d^{2}}{4}\right) \not y_{n} S-1 / 2 \rho C_{D} N y_{n} d V^{2}$

Rearranging and replacing the parameter " $a$ " with $\frac{f}{8}$ gives the velocity under the influence of bed shear and stem drag as

$V=\frac{1}{F_{f}} \sqrt{S}$

where the resistance coefficient 
where $=\frac{1}{F_{f}}=\sqrt{\frac{1-\frac{N \pi d^{2}}{4}}{f / 8+1 / 2 \rho C_{D} N y_{n} d} g y_{n} \ldots}$

As flows depth decreases, the contribution of bed shear to total resistance becomes more significant.

\subsection{Sediment transport and deposition}

The phenomenon of sediment transport is related to many variables, some of which are interrelated and dependent on each other. Basing on field data, Yang and Lim (2003) and Yang(2005) introduced a parameter $T_{T}$ which provides a good linear relationship with sediment discharge $g_{t}$, i.e.

$$
\begin{aligned}
& g_{t}=k T_{T} \\
& T_{T}=\frac{\gamma_{s}}{\gamma_{s}-\gamma} \tau_{o} \frac{u_{*}^{\prime 2}-u_{*_{c}}^{2}}{w_{s}}
\end{aligned}
$$

where $T_{T}$ is the total load transport parameter, $k$ is a constant, $\tau_{\mathrm{o}}$ is the overall bed shear stress as given by Equation (16), $w_{s}$ is the particle fall velocity and $u_{*}$ is the critical shear velocity and $\mathcal{u}$ is the shear velocity given as

$$
u_{*}^{\prime}=V /\left(2.5 \ln \frac{11 y_{n}}{d_{50}}\right)
$$

If $\quad u_{*}^{2}>u_{*_{c}}^{2}$ and introducing $\tau_{o}=\rho g R S$, sediment discharge can be written in terms of sediment concentration as follows

$$
\frac{g_{t}}{q}=C_{t}=k\left(\frac{\gamma_{s \gamma}}{\gamma_{s}-\gamma}\right) \frac{u_{*}^{2} S}{V w_{s}} \frac{R}{y_{n}}
$$

where $R$ is the hydraulic radius and $S$ is the energy slope. If $S$ is expressed in terms of flow velocity as $=V^{2} /\left(C^{2} R\right)$, in which $C$ is Chezy's coefficient, and if it is introduced in Equation (24) and applying Equation (23), sediment concentration becomes

$$
C_{t}=k_{o}\left(\frac{V^{3}}{w_{s}}\right)
$$

where

$$
k_{o}=k\left(\frac{\gamma_{s} \gamma}{\gamma_{s}-\gamma}\right) \quad \int y_{n}\left(2.5 C \ln \frac{11 y_{n}}{d_{50}}\right)^{2 \cdots}
$$

Therefore, depending on the size and density of the bed material and the flow conditions, sediment particles can be transported by the flow in the form of bed load and suspended load as long as $u_{*}^{2}>>u_{*_{c}}^{2}$. In this situation, there is no deposition in the channel and the one-dimensional depth integrated mass transport equation for a channel with a constant cross-section with respect to $x$ is given as (Partheniades, 1992)

$$
\frac{\partial C_{s}}{\partial t}+V \frac{\partial C_{s}}{\partial x}=\frac{1}{A} \frac{\partial}{\partial x}\left(A D_{x} \frac{\partial C_{s}}{\partial x}\right)
$$

where $C_{s}$ is the suspended sediment concentration, $A$ is local cross-sectional area of the channel, and $D_{x}$ is the dispersion coefficient. For a uniform flow conditions and in the absence of density gradients, $D_{x}$ is constant and equal to $D_{t}$, in which case Equation (27) becomes

$$
\frac{\partial C_{s}}{\partial t}+V \frac{\partial C_{s}}{\partial x}=D_{x} \frac{\partial^{2} C_{s}}{\partial x^{2}}
$$

If a constant concentration, $C_{s o}$ is being maintained at $x=0$ and applying appropriate boundary conditions, i.e. $C_{s}(0, t)=C_{s o}$ for $t \geq 0$, $C_{s}(x, 0)=0$ for $x>0$ and at $x=\infty$ the concentration $C_{s}$ will be zero all the time, then the solution of Equation (28) reduces to a simple form

$$
\frac{C_{s}}{C_{s o}}=\exp \left(-\frac{V_{o} x}{D_{t}}\right)
$$

As we go along the $x$-axis and as $u_{*}^{2} \rightarrow u_{*_{c}}^{2}$, sediments begin to be deposited. With a given settling velocity, the rate at which suspended sediment is deposited depends on the decrease in current speed or the ratio between the stress at the bed and the critical depositional shear stress required to deposit grains of a given size. Based on experimental observation, the rate of 
deposition for grains of a given settling velocity is given as (Brown et al. (1989)):

$$
R_{d}=C_{b}\left(1-\frac{\tau_{o}}{\tau_{c}}\right)
$$

Where $C_{b}$ is the concentration of sediment near the bed and $\tau_{c}$ is the critical shear stress.

\section{MATERIALS AND METHODS}

Water discharge and rainfall data sets for Simiyu River watershed were obtained from the data bank of the Tanzania Meteorological Agency Office in Mwanza. The water discharge data are those measured at the Simiyu River Road Bridge (STATION ID: 01.12.02.2).

Sampling in Magu Bay was conducted aboard an $8 \mathrm{~m}$ outboard engine wooden boat. Speed of currents and turbidity were measured using an "AANDERAA" self-recording current meter model 9 (RCM9). The current meter is a selfcontained instrument that could be moored in the lake for long periods of time. It measures horizontal current speed and direction, temperature, salinity, turbidity as well as pressure from which the water depth above the instrument can be deduced. Water depth was also measured using an echo-sounder type FISHIN' BUDDY II. Geographical locations of the sampling stations were obtained using a GPS, Model Garmin 12. Suspended sediment concentrations were found by filtering and then weighing the sampled water,. The sampling procedure was rather simple. Water samples were taken in the middle of the water column by immersing sampling bottles into the turbulent flowing water at the river mouth and at various stations in the Bay.

Water transparency was determined by using a $20 \mathrm{~cm}$ diameter Secchi disk. Suspended particulate matter was determined by filtering a known volume of water through preweighed (A) glass micro fiber filters. In the laboratory the filters were dried in an oven at $50 \circ \mathrm{C}$ temperature to constant weight, B. The weight of the suspended particles was obtained by subtracting weight $B$ from $A$.

\section{RESULTS AND DISCUSSION}

Figure 5 shows results of statistical the expected cumulative rainfall and water discharge for various return periods using Weibull Distribution Function $\left(k_{w}=2\right)$. It can be seen that cumulative rainfall of $1043 \mathrm{~mm}$ and the respective discharges of $98.5 \mathrm{~m}^{3} / \mathrm{s}$ have a return period of 5 years. A return period of 50 years is expected to have cumulative rainfall of $1403 \mathrm{~mm}$ and discharges of $156.7 \mathrm{~m}^{3} / \mathrm{s}$.

As the river enters the lake the width of the river channel suddenly increases. The sudden widening of the river channel and the presence of the vegetation at the river mouth result in energy loss of the flow. Consequently sediment deposition increases and the depth of the channel decreases longitudinally from the river mouth until it reaches a minimum of $0.8 \mathrm{~m}$ at a distance $X_{o}=0.52 \mathrm{~km}$ as shown in Figure 6A. Although the theoretical value of $X_{o}$ is 0.32 , the field value of $0.52 \mathrm{~km}$ is quite close and may be fluctuating depending on the variation of water discharge with seasons.

Concentration of suspended particles was highest at the river mouth $(1575 \mathrm{mg} / \mathrm{l}$ at station 1 and exponentially decreased as one moves away from the river $(0.9 \mathrm{mg} / 1$ at station 8 , a station that was most off-shore from the river mouth). Also, turbidity was higher towards the river and decreased as one moves away from the river mouth. At a distance half a kilometre longitudinally from the river mouth, most of the sediment has been deposited and only a concentration of $533 \mathrm{~g} / 1$ is remaining. Fitting the data with an exponential decay function in accordance with Equation (29) sediment concentration is generally attenuated exponentially and the attenuation coefficient was found to be 2.1.

Water temperature did not vary much between stations; it ranged from $26{ }^{\circ} \mathrm{C}$ to $28{ }^{\circ} \mathrm{C}$ for surface water and from $24 \circ \mathrm{C}$ to $26 \circ \mathrm{C}$ for bottom water. In the first 1.5 kilometres longitudinally from the river mouth, surface and bottom temperatures are the same. From there onwards, as water depth increases, the surface temperature varies very little with distance. However, the bottom temperature decreases with distance from the river mouth. 
Figure 6B shows that suspended sediment concentration is directly related to current speed as proposed in Equation (25). At the mouth of the river, the surface and bottom current are northward $\left(60^{\circ}\right.$ clockwise with respect to the North). At Station 2, which is 0.52 $\mathrm{km}$ from the river mouth, the current speed has been strongly attenuated from $0.54 \mathrm{~m} / \mathrm{s}$ to 0.07 $\mathrm{m} / \mathrm{s}$. From there onwards, the current speeds are reversed, almost flowing in the opposite direction of the river flow (250 clockwise with respect to the North). This is probably why most of the suspended sediments are deposited here. Figure 6C shows that the current speed decays exponentially according to the equation $V=54 e^{-3.9 x}$.

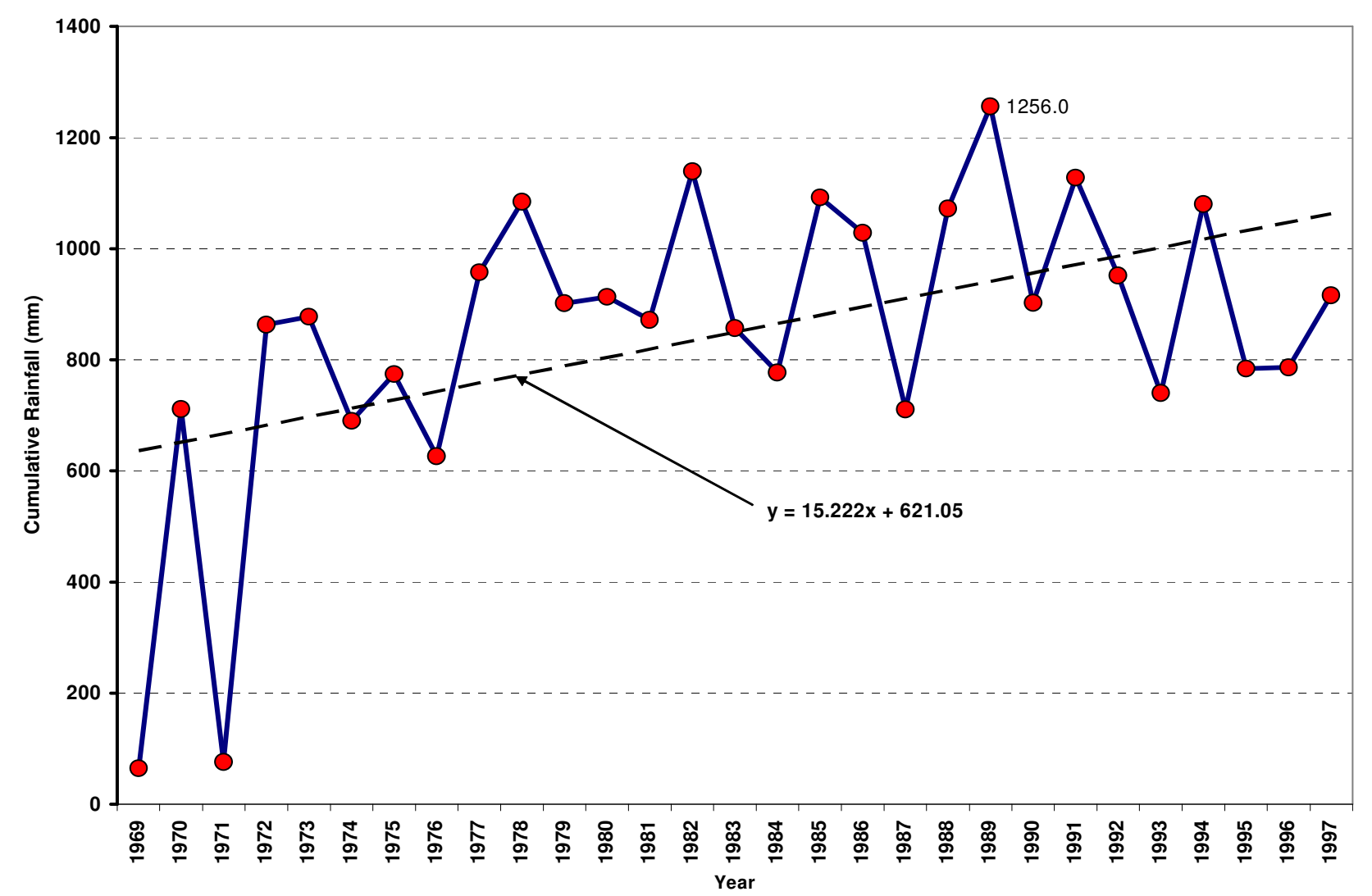

Figure 3. Cumulative rainfall recorded at Ndagalu Rainfall Station (STATION ID: 92.334) for the period 1969 - 1997. 


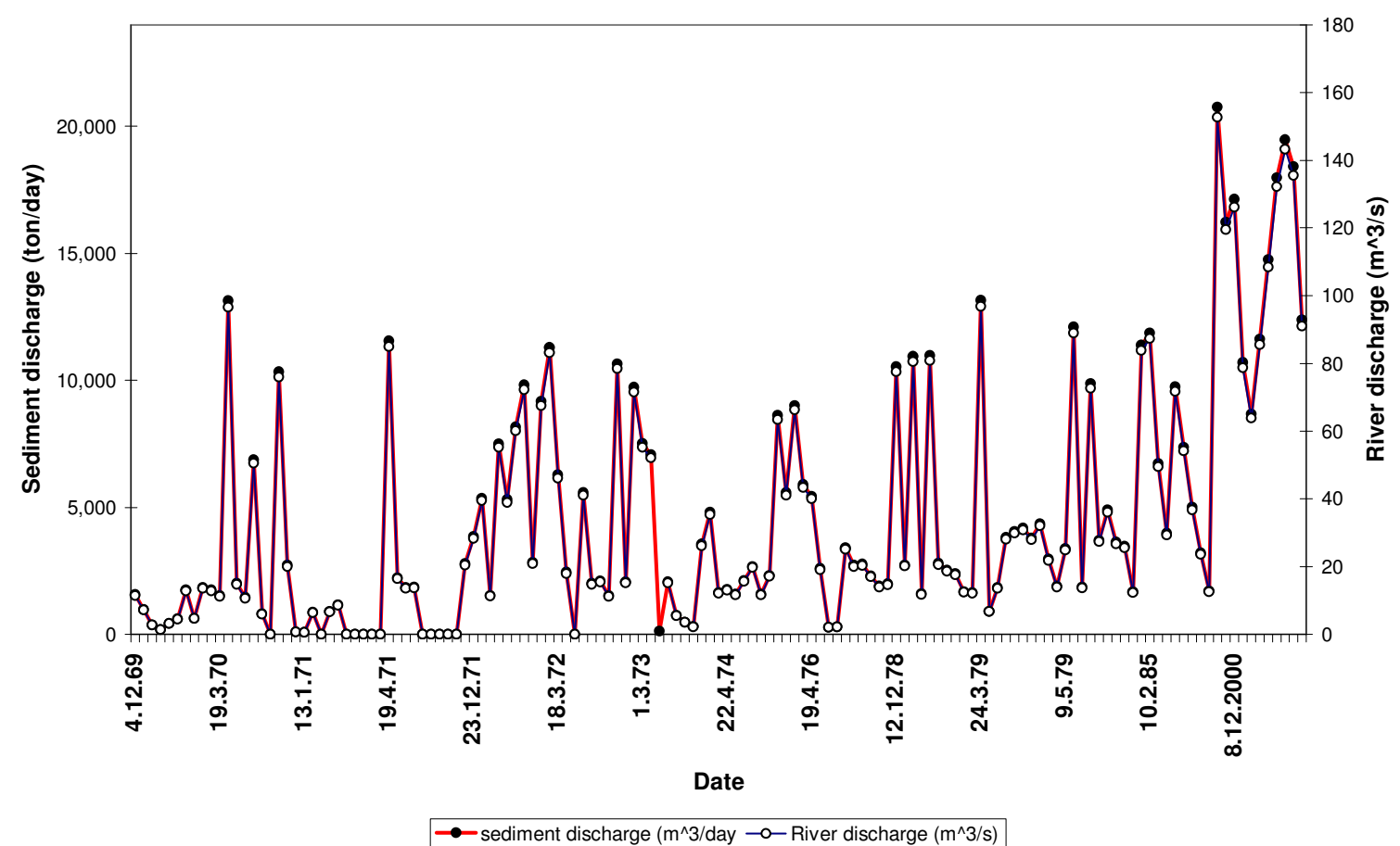

Figure 4. Water discharge recorded at Simiyu River Road Bridge (STATION ID: 01.12.02.2) and estimated sediment discharge

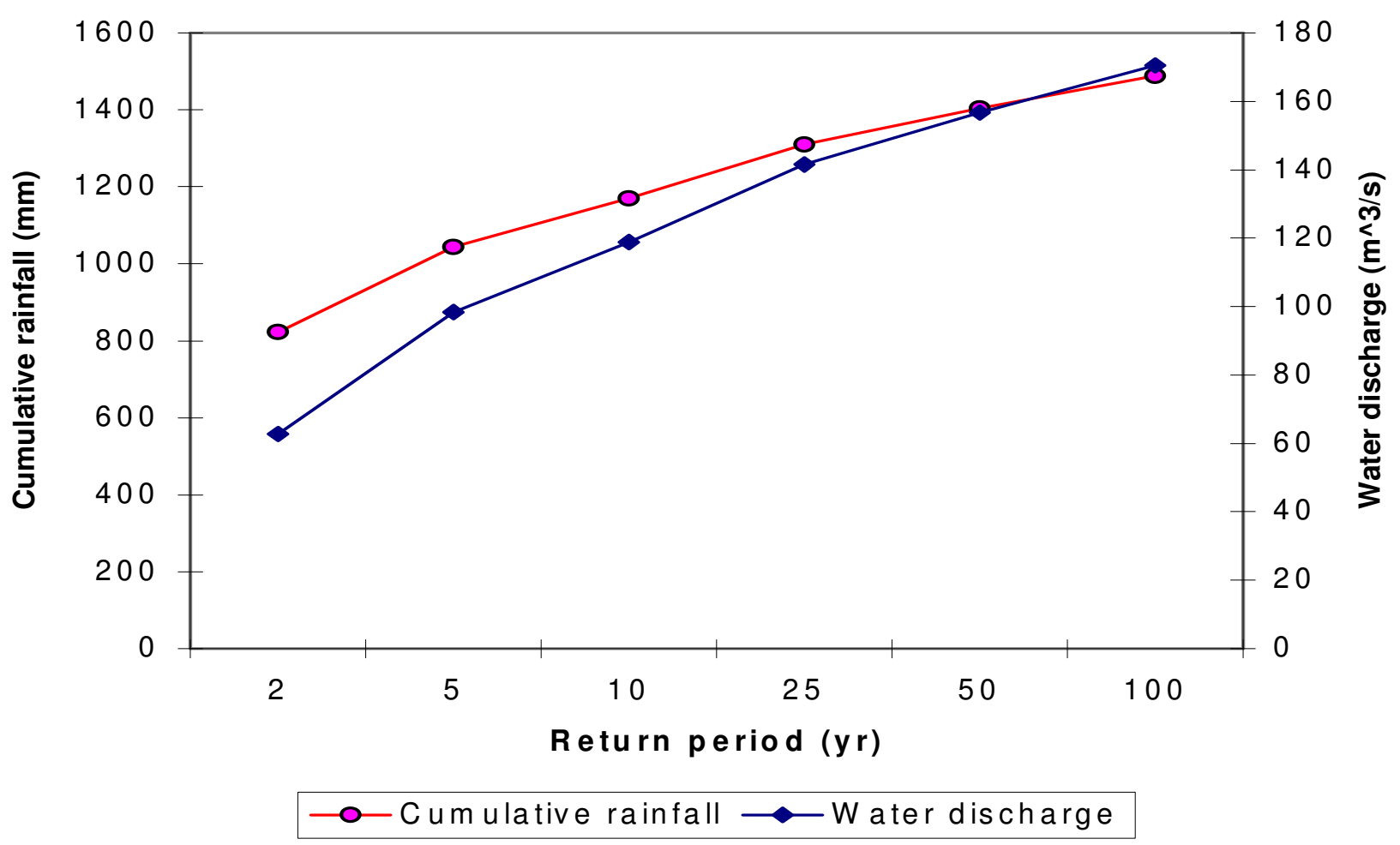

Figure 5. Expected cumulative rainfall and water discharge for various return periods using Weibull Distribution Function $\left(k_{w}=2\right)$ 

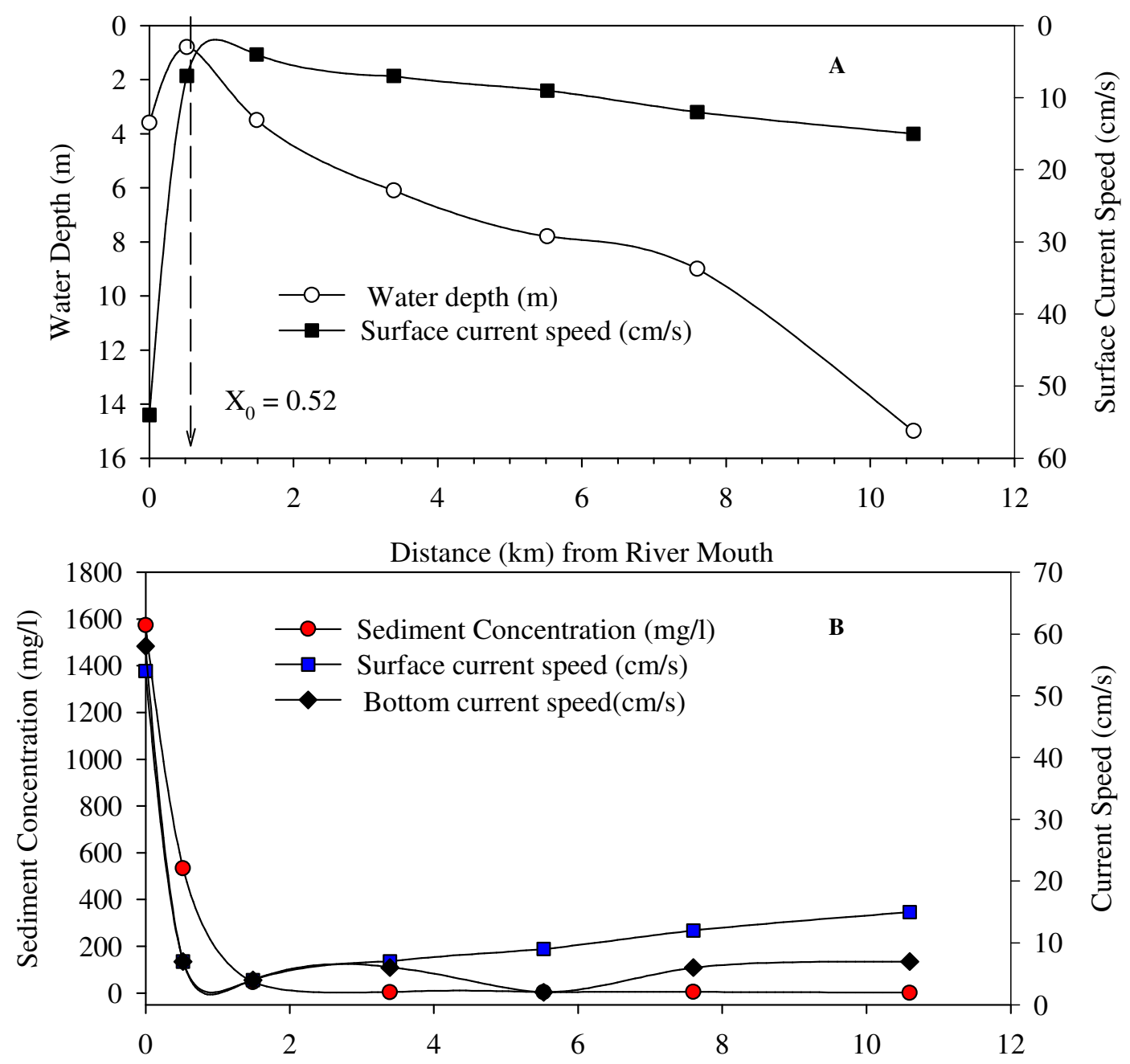

Distance $(\mathrm{km})$ from River Mouth

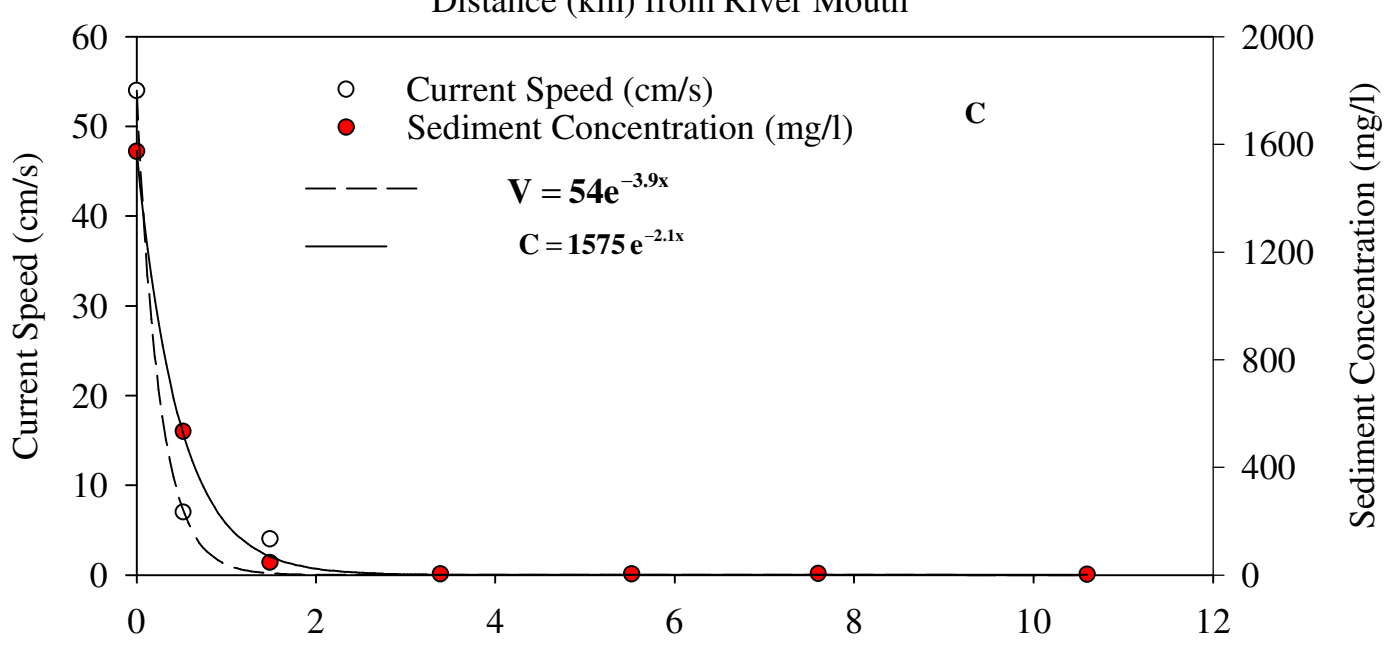

Distance $(\mathrm{km})$ from the River Mouth

Figure 6. Variation of current speed and sediment concentration with longitudinal distance from the river mouth. 


\section{CONCLUSION}

It is pertinent to conclude that Simiyu river is a significant supplier of sediment into Magu Bay. Deposition of suspended sediments takes place mainly within the first half kilometre from the river mouth. However, according to observations by Yanda et al. (2001), less than $10 \%$ of the sediments in Simiyu river basin ever reach the lake. Most of the suspended sediments from Simiyu river water are trapped by the fringing macrophytes at the mouth of the river. Therefore, the attenuation of the sediment load to the lacustrine environment is quite tremendous. The sediments that escape to the inshore lake waters are probably less than $5 \%$ of the total sediment load in the Simiyu River basin. The present study shows that there is a clear need of assessing the sediment trapping efficiency of Magu bay wetland macrophytes. It is recommended that a comprehensive long-term study to cover all major rivers entering the lake be undertaken.

\section{REFERENCES}

1. Brown, J., A. Colling, D. Park, J. Phillips, D. Rothery and J. Wright. (1989). In G. Bearman (Ed.). "Waves, Tides and Shallow Water Processes". Pergamon Press in Association with The Open University. 187 pp.

2. Goda, Y. (1988). “On the Methodology of Selecting Design Wave Heights", Proceedings, 21st International Conference on Coastal Engineering , American Society of Civil Engineers, Costa del Sol-Malaga, Spain, pp. 899-913.

3. Gringorten, I. I. (1963) “A plotting Rule for Extreme Probability Paper," Journal of Geophysical Research, Vol. 68, No. 3, pp. 813-814.

4. Guo, J. (2002). “Logarithmic Matching and its Applications in Computational Hydraulics and Sediment Transport". Journal of Hydraulic Research, Vol. 40, No. 5. pp $555-565$.

5. Hamza, M.M. (1996). Determination of heavy metal pollution in Lake Victoria using
Energy Dispersive X-ray Fluorescence analysis. MSc. Dissertation, University of Dar es Salaam. 69 pp.

6. James, C. S., A. L. Birkhead and A.A. Jordanova and J. J. O' sullivan (2004). Flow resistance of emergent vegetation. Journal of Hydraulic Research Vol.42 No. 4 (2004) pp $390-398$

7. Johanson, T.C., Scholz, C.A., Talbot, M.R., Kelts, K, Ricketts, R.D., Ngobi, G., Beuning, K., Ssemanda, I. and McGill, J.W. (1996). Late Pleistocene desiccation of Lake Victoria and rapid evolution of Cichlid fishes. Science 273: 1091-1093.

8. Lehman, J.T. 1996. Pelagic food webs of the East African Great Lakes. In: : Johnson, I.C. and Odada, E.O. (eds) The Limnology, Climatology and Paleontology of the East African Lakes. Gordon and Breach Publishers, Amsterdam. Pp. 281-301

9. Mpendazoe, M.T.F., Kibogoya, M., Rutagemwa, K.D., S. Kayombo, M. Rugasira, and P. Marwa (1993). Evaluation of point source discharge treatment options in Lake Victoria area in Tanzania. World Bank report, Dar es Salaam. 48 pp.

10. Mtega, N and V.G. Masanja (1999). "Modelling pollutants discharge in river Mahina Mwanza - Tanzania: The case of oxygen dynamics from a spatial source." In Mushi, A and A. Bijura (Eds). Proceedings of the $2^{\text {nd }}$ International Conference on Mathematics for Industry. 21 st $-23^{\text {rd }}$ September 1999, University of Dar es Salaam, Tanzania.

11. Mtega, $N$ and V.G. Masanja (1999). "Comparison of Numerical and Analytical Simulations of Pollutants in Lake Victoria: The case of oxygen dynamics from a spatial source." In Mushi, A and A. Bijura (Eds). Proceedings of the $2^{\text {nd }}$ International Conference on Mathematics for Industry. 21 ${ }^{\text {st }}$ -23rd September 1999, University of Dar es Salaam, Tanzania. 
12. Partheniades, E. (1992). "Estuarine Sediment Dynamics and Shoaling Processes". In Herbich, J.B. (Ed.), "Handbook of Coastal and Ocean Engineering", Vol. 3. Harbors, Navigational Channels, Estuaries, Environmental Effects". Pp 985 - 1071.

13. Stager, J.C., Cumming, B., and Meeker, L., 1997. A high-resolution 11,400 Yr diatom record from Lake Victoria East Africa. Quaternary Research 47: 81-89
14. Yanda, P.Z., Shishira, E.K., Madulu, N.F. and Kauzeni, A.S. 2001. "Soil erosion hazard mapping as a basis for identifying priority areas for conservation in Lake Victoria basin". A paper presented at the National LVEMP Technical Workshop 6th -10th August, 2001, Mwanza. 